\title{
Cancer Stem Cell plasticity - a deadly deal
}

Archana $\mathrm{PT}^{1,2 \#}$, Kritika Saxena ${ }^{3 \#,}$ Reshma Murali ${ }^{1}$, Mohit Kumar Jolly ${ }^{3 *}$ Radhika Nair $^{1 *}$

${ }^{1}$ Cancer Research Program, Rajiv Gandhi Centre for Biotechnology, Kerala, India

${ }^{2}$ Manipal Academy of Higher Education (MAHE), Manipal, India

${ }^{3}$ Centre for BioSystems Science and Engineering, Indian Institute of Science, Bangalore, India \#Co-Authors

*Co-corresponding authors

*Correspondence to radhikanair@rgcb.res.in or mkjolly@iisc.ac.in 


\begin{abstract}
Intratumoral heterogeneity is a major ongoing challenge in the effective therapeutic targeting of cancer. Accumulating evidence suggests that a fraction of cells within a tumor termed Cancer Stem Cells (CSCs) are primarily responsible for this diversity resulting in therapeutic resistance and metastasis. Adding to this complexity, recent studies have shown that there can be different subpopulations of CSCs with varying biochemical and biophysical traits resulting in varied dissemination and drug-resistance potential. Moreover, cancer cells can exhibit a high level of plasticity or the ability to dynamically switch between CSC and non-CSC states or among different subsets of CSCs. The molecular mechanisms underlying such plasticity has been under extensive investigation and the trans-differentiation process of Epithelial to Mesenchymal transition (EMT) has been identified as a major contributing factor. Besides genetic and epigenetic factors, CSC plasticity is also shaped by non-cell-autonomous effects such as the tumor microenvironment. In this review, we discuss the recent developments in understanding CSC plasticity in tumor progression at biochemical and biophysical levels, and the latest in silico approaches being taken for characterizing cancer cell plasticity with implications in improving existing therapeutic approaches.
\end{abstract}

Key words: Cancer stem cells, Plasticity, Epithelial-Mesenchymal Transition, Metastasis, Microenvironment 


\section{Introduction}

Heterogeneity in cancer biology has long been recognized and exploited in the clinical management of the disease (Rich 2016). Intertumoral heterogeneity within breast cancer patients for example, exhibiting different molecular subtypes based on immunohistochemical markers like Estrogen Receptor (ER) or Her2 has been the basis of successful targeted therapeutic approaches (Turashvili and Brogi 2017, Januskeviciene and Petrikaite 2019). The inbuilt cellular variation within a tumor has been shown to be an important driver for the emergence of therapy resistant clones which ultimately lead to recurrence and spread of the cancer cells resulting in patient mortality(Somasundaram, Villanueva et al. 2012, Dagogo-Jack and Shaw 2018, Akgul, Patch et al. 2019).

The development of intratumoral divergence in tumor cells has been widely attributed to two contrasting processes (Shackleton, Quintana et al. 2009, Prasetyanti and Medema 2017). The clonal evolution theory takes into account the intrinsic differences between all cells based on genetic and epigenetic programs as well as the influence of the tumor microenvironment (TME). The fitter clones are selected for and contribute to the diversity of the tumor cell population (McGranahan and Swanton 2017). The second model - Cancer Stem Cell (CSC) model - proposes that there are a sub set of cells (termed CSCs) which are predisposed to drive the tumor progression, metastatic and therapeutic resistance of the entire tumor. In this hierarchical model, CSCs can differentiate into less self-renewing populations of non-CSCs which form the bulk of the tumor, in an analogous fashion to stem cell development (Vermeulen, de Sousa e Melo et al. 2012). More recently, the ability of cells to switch states via different programs like Epithelial-Mesenchymal Transition (EMT) has given rise to the concept that plasticity can allow CSCs to interchangeably develop into non-CSCs and viceversa (Chaffer, Brueckmann et al. 2011, Marjanovic, Weinberg et al. 2013, Gupta, Pastushenko et al. 2019). Moreover, different subsets of CSCs can lie on various points on the epithelialmesenchymal axis (Liu, Cong et al. 2014, Bocci, Jolly et al. 2018, Bocci, Gearhart-Serna et al. 2019). The indirect implication of this plasticity model is that the clonal evolution and CSC models are not mutually exclusive and ushers in more complexity to the manner in which heterogeneous cell populations arise within a tumor (Cabrera, Hollingsworth et al. 2015).

The direct consequence of evolving populations in a tumor through inter conversion by plasticity programs is the rise of drug resistant and metastatic cells which are ultimately 
responsible for the mortality associated with cancer (Biddle, Gammon et al. 2016, Doherty, Smigiel et al. 2016). The need of the hour is hence to understand the molecular underpinnings for CSC plasticity with a focus on discerning a detailed characterization and decoding the impact of bidirectional nature of CSC plasticity on the clinical management of the disease.

\section{CSC heterogeneity and plasticity in tumor progression}

The concept that CSCs are dynamic populations and can undergo spontaneous state transitions has been strengthened by various studies (Chaffer, Brueckmann et al. 2011, Gupta, Fillmore et al. 2011, Chaffer, Marjanovic et al. 2013). In the study done by Chaffer et al. (Chaffer, Brueckmann et al. 2011). using basal-like breast cancer cells, non-stem cells were shown to spontaneously switch to stem-like cells in vitro and in vivo; this plasticity was later found to be regulated by ZEB1 - a key regulator of EMT (Jia, Jolly et al. 2017). CSC heterogeneity and plasticity has been observed in different cancers. Just like their non-cancerous counterparts, identification of CSCs has been mainly based on the expression of cell surface markers (Chen, Dong et al. 2016). However, even within a single tumor type, different markers can identify distinct CSCs which are phenotypically distinct and could vary from patient to patient depending on the genetic make-up of the tumor (Tang 2012). For instance, in glioblastoma, multiple markers like CD133, CD44, A2B5, SSEA have been utilized for identifying the stem cell populations (Singh, Hawkins et al. 2004, Ogden, Waziri et al. 2008, Son, Woolard et al. 2009). However, the use of CD133 marker is controversial as CD133- cells have also been shown to form tumors in glioma and $\mathrm{CD} 133^{+}$cells could be derived from $\mathrm{CD} 133$ - cells in vivo, implying the underlying plasticity (Wang, Sakariassen et al. 2008). A recent study by Dirkse et al found that in glioblastoma, the cell- membrane associated CSC markers such as CD133, A2B5, SSEA and CD15 does not represent a clonal entity but a plastic state which can be adapted by most of the cells in response to varying conditions in the microenvironment. They also proposed that the enhanced tumorigenic potential of CSC-like state is a result of faster adaptation of the cells to the microenvironment (Dirkse, Golebiewska et al. 2019).

The evidence for plasticity of CSC states comes from melanoma as well. A slow cycling population of melanoma CSC-like cells were identified using H3K4 demethylase JARID1B as a biomarker (Roesch, Fukunaga-Kalabis et al. 2010). Intriguingly, the expression of this marker was dynamically regulated and JARID1B-negative cells could re-express the marker indicating the dynamic nature of the stemness trait. Another seminal study done on melanoma supports 
the phenotypic plasticity model of stem-like cells. In this study, they found that in melanomas from patients, phenotypically distinct cells can recapitulate the original tumor and these cells can undergo reversible phenotypic changes in vivo (Quintana, Shackleton et al. 2010). In breast cancer, different subsets of CSCs were identified based on ALDH1, CD44, and CD24; and the two subpopulations (epithelial-like ALDH1+, mesenchymal like CD44+/CD24-) were shown to be capable of inter converting among themselves as well as give rise to non-CSCs (Liu, Cong et al. 2014). Moreover, in breast cancer, CSCs and non-CSCs were shown to exhibit dynamic equilibrium maintained by cytokine-mediated crosstalk among these distinct populations (Iliopoulos, Hirsch et al. 2011). These results suggest that at least in some cancers, phenotypic plasticity is reversible and does not necessarily depend on genetic alterations (Jolly, Kulkarni et al. 2018).

Another compelling evidence for CSC plasticity in tumor progression comes from studies on colorectal cancer. Targeted ablation of Lgr5+ CSC did not lead to tumor regression in vivo as the differentiated marker negative cells could give rise to marker positive population which sustained the tumor growth. But interestingly they could not form liver metastases (de Sousa e Melo, Kurtova et al. 2017), suggesting that the contribution of CSCs in primary tumor formation and that in metastatic settings may be different. More recently, some markers for metastatic CSCs have been identified across cancers (Celia-Terrassa and Jolly 2019).

CSC plasticity has also been observed alongside vasculogenic mimicry (VM) - a hallmark process of cancer cell plasticity in which cancer cells transdifferentiate and acquire endothelial cell like characteristics (Fernandez-Cortes, Delgado-Bellido et al. 2019). In triple negative breast cancer, a CD133+ cell population with CSC-like traits was found to show the ability to form tube-like structures (Liu, Sun et al. 2013). In renal cell carcinoma, using immunohistochemistry analysis of patient samples, the expression of stem cell like markers CD133 and CD44 was found to correlate with VM and high CSC marker expression and VM correlated with poor survival (Zhang, Sun et al. 2013).

\section{Biochemical characterization of cancer stem cells and their subsets}

The concept of cancer stem cell plasticity relies on the dynamic ability to shift from a CSC state to a non-CSC state and vice versa (Cabrera, Hollingsworth et al. 2015). CSC plasticity can be instigated by various components in the microenvironment such as the secretion of cytokines and chemokines, communication with different stromal cell types and extracellular matrix and hypoxia (Agliano, Calvo et al. 2017). Consequent activation of transcription factors 
and/or epigenetic modifications have been shown to mediate this interconversion. To understand the biology of CSC plasticity and the mechanisms underlying their functional phenotype with the aim of developing efficient treatment strategies, an essential requirement is the characterization and methods to selectively isolate the plastic CSC population from heterogeneous tumors.

One of the serious and longstanding challenges in studying CSCs is the determination of appropriate methodology for the isolation and characterization of CSCs (Agliano, Calvo et al. 2017). One of the most widely applied method to identify CSCs is to sort the cells based on the expression of cell surface markers such as CD44, CD133, CD24, CD26, EPCAM, CD166 (Jaggupilli and Elkord 2012, Chen, Huang et al. 2013) or based on enzymatic activity of intracellular proteins like ALDH1 (Pattabiraman and Weinberg 2014). However, even these markers are not universally expressed on all CSCs, limiting their use in few cancers (Jaggupilli and Elkord 2012). To overcome this limitation, more than one markers are used together in several cancers (Agliano, Calvo et al. 2017). Although multiple markers have been described, the lack of reliable and accurate markers is still a stumbling block in the identification of CSCs. Moreover, recent single cell transcriptome analyses revealed that many CSC markers could be co-expressed by a single cell at the same time (Patel, Tirosh et al. 2014, Eun, Ham et al. 2017) and the expression of CSC markers could vary in vivo as a consequence of plasticity and adaptation to the microenvironment (Dirkse, Golebiewska et al. 2019). This clearly highlights the heterogeneity of CSCs and inefficiency of the markers currently in use in distinguishing CSCs and non-CSCs. These results pinpoint the need for better understanding of CSC heterogeneity and also the necessity to re-evaluate the idea of developing CSC marker-based therapeutic approaches. Therefore, combining marker-based isolation strategies with functional assays such as in vitro clonogenic and in vivo limiting dilution xenotransplantation assays are of paramount importance to validate the stemness trait of the cells (Dirkse, Golebiewska et al. 2019, Prager, Xie et al. 2019).

\section{Biophysical characterization of CSCs and their subsets}


The properties of stem cells such as self-renewal, multipotency and maintenance of an undifferentiated cell state have been shown to be governed by intracellular and extracellular components present in their microenvironment constituting the stem cell niche (Morrison and Spradling 2008). Similar to stem cells, properties of cancer stem cells (CSCs) are regulated by the tumor microenvironment (TME) which can enhance metastasis and tumor initiation capabilities of CSCs (Aponte and Caicedo 2017). CSCs, on the other hand, can also remodel ECM more strongly as compared to bulk cancer population (Srinivasan, Ashok et al. 2017); thereby setting a complex feedback loop among the CSC and its niche. Biochemical constituents of such loops have been well-characterized earlier (Korkaya, Liu et al. 2011). Recent evidence suggests how biophysical cues such as matrix stiffness, cell contractility and cell-matrix adhesion strengths can regulate the tumor-initiating properties of CSCs. For instance, blocking ROCK (Rho-associated protein kinase) can inhibit cell contractility and invasion potential of breast cancer stem cells (Srinivasan, Ashok et al. 2017). At a biophysical level, TME is often characterized by increased stiffness due to ECM remodeling, increased compressive stress due to confined growth, enhanced interstitial pressure and an increased interstitial fluid flow (Zanotelli, Goldblatt et al. 2018). Extrinsic mechanical forces exerted by ECM constituents can trigger biochemical changes inside cells such as cytoskeleton rearrangement, and changes in gene expression, protein-protein interactions and enzyme modifications, thus converging on various mechano-transduction and mechano-chemical axes (Ogden, Waziri et al. 2008, Broders-Bondon, Nguyen Ho-Bouldoires et al. 2018, Roy Choudhury, Gupta et al. 2019)

Cancer cells display variations in response to extrinsic biomechanical stimuli, leading to heterogeneity in their biophysical properties, which influences the overall nature of cells such as stemness and differentiation. Recent studies have shown that mechano-biological cues greatly influences the generation and maintenance of CSCs and eventually metastasis (Chen and Kumar 2017). In addition, mechanical properties such as deformability and adhesiveness are different for CSCs as compared to the bulk tumor population (Saliba, Saias et al. 2010, Zhang, Kai et al. 2012, Babahosseini, Ketene et al. 2014, Chen, Zhou et al. 2016). These advances have enabled attempts to isolate and identify CSCs based on biophysical marker using engineering techniques such as microfluidic devices (Saliba, Saias et al. 2010, Gossett, Tse et al. 2012, Zhang, Kai et al. 2012, Liu, Lee et al. 2015, Chen, Zhou et al. 2016) in a label-free manner. 
For instance, CSCs were enriched based on their adhesive traits using a microfluid chip having micro-channels coated with basement membrane extract. The cells entered into the chip driven by hydrodynamic forces. While highly adhesive cells were captured in micro-channels, less adhesive cells were collected from the outlet, which were shown to be enriched in cancer stem cells, had greater motility and were resistant to chemotherapeutic drugs (Zhang, Wu et al. 2015). This study emphasizes the interconnections between EMT, stemness, and drug resistance (Jolly, Somarelli et al. 2019), and the use of microfluidics in investigating these associations (Nath, Bidkar et al. 2019). Similarly, a microfluidic device fitted with microbarriers was used to isolate cancer cells based on their deformability in vitro. The more deformable flexible phenotype was associated with expression of many genes involved in motility, metastasis and greater mammosphere formation efficiency (Zhang, Kai et al. 2012). Consistently, in vivo, deformability has been shown to be crucial for efficient extravasation of tumor-repopulating cells during metastasis as seen in zebrafish models (Chen, Zhou et al. 2016).

Similar to biochemical heterogeneity observed within CSCs (Bocci, Gearhart-Serna et al. 2019, Moreira, Brayner et al. 2019), CSCs can be biophysically strikingly different too In a recent study, Chen et al., showed the association of biophysical properties of CSCs and their ability to invade, migrate, and initiate tumors, using the SUM149 inflammatory breast cancer (IBC) stem cells (Chen, Allen et al. 2019). In this study, the authors sorted SUM149 CSCs based on the expression of aldehyde dehydrogenase enzyme (ALDH) and assayed biophysical properties of ALDH+ and ALDH- cells in terms of deformability, adhesion strength and contractility. $\mathrm{ALDH}+$ cells displayed greater deformability, lower adhesion strength and reduced contractility relative to ALDH- cells, and resulted into enhanced functional phenotypes in vitro and greater tumor development in vivo. In addition, to validate the contribution of biophysical properties in metastasis, the authors isolated IBC cells based on their adhesive property using a microfluidic device and showed that the less adhesive cell population was ALDH+ enriched, displayed enhanced in vitro invasion and migration as well as increased in vivo tumor development. Further, exogenous alteration of cell stiffness also resulted in changes in metastatic potential of these cells with less stiff cells showing greater invasion and migration (Chen, Allen et al. 2019). The results observed in this study corroborated well with earlier studies showing that cancer cells with greater deformability, lower adhesion strength and lower contractile force show enhanced metastatic potential (Swaminathan, Mythreye et al. 2011, 
Kraning-Rush, Califano et al. 2012, Byun, Son et al. 2013, Sun, Luo et al. 2016, Bongiorno, Gura et al. 2018).

Therefore, with increasingly detailed characterization of biomechanical properties of various subpopulations of cancer cells and ECM, a 'mechanosome' or 'matrisome' signature may be helpful in identifying and isolating the most aggressive cancer cell subpopulations (Roy Choudhury, Gupta et al. 2019).

\section{Single cell methods to identify CSCs and their subsets}

Much of our current understanding about CSCs comes from studies performed on bulk cancer cell populations. However, bulk analysis masks the underlying intra-tumor heterogeneity and does not inform much about rare cell subpopulations within the tumor (Navin 2015, Bhatia, Monkman et al. 2019). Therefore, it becomes extremely critical to study the cancer cells at a single-cell resolution to better comprehend the CSC heterogeneity and plasticity (Etzrodt, Endele et al. 2014). Flow cytometry and Fluorescence Associated cell Sorting (FACS) is a widely used method for the isolation and characterization of single CSCs (Greve, Kelsch et al. 2012, Etzrodt, Endele et al. 2014). In an interesting work done by Dirkse et al., by combining FACS analysis of CSC markers and functional assays such as proliferation, self-renewal and multipotency tests, they found that glioblastoma stem cell heterogeneity results from tumor plasticity which is determined by the microenvironment cues (Dirkse, Golebiewska et al. 2019). Lineage tracing methods have also been utilized by researchers to decipher the properties of CSCs and has huge potential in understanding the transition of cell states. Using intra-vital in vivo lineage tracing method in a genetic mouse model of breast cancer, Zomer et al, have shown the existence of CSCs in unperturbed mammary tumor for the first time. They also found that CSC state is plastic and can be activated, lost or deactivated (Zomer, Ellenbroek et al. 2013). In another study, lineage tracing and transcriptional analysis of Notch1 expressing cells of intestinal tumors has led to the identification of a previously uncharacterized and undifferentiated stem cell population that contribute to tumor progression and heterogeneity (Mourao, Jacquemin et al. 2019).

The advent of single-cell omics approaches has revolutionized our knowledge on CSC biology. Single cell genomic and transcriptomic analyses have provided invaluable insights regarding the intra-tumor heterogeneity and clonal evolution in different cancers (Patel, Tirosh et al. 2014, Eirew, Steif et al. 2015, Hou, Guo et al. 2016, Puram, Tirosh et al. 2017). In addition to 
discerning the dynamics of clonal evolution, single cell OMIC methods have also enabled the identification of cancer stem cell state transitioning and its contribution to drug resistance (Puram, Parikh et al. 2018, Sharma, Cao et al. 2018). Considering the rarity of a cancer stem cell, combining single cell transcriptomics with enrichment strategies like flow cytometry or sphere assays will drastically improve the characterization of CSC (Akrap, Andersson et al. 2016, Jonasson, Ghannoum et al. 2019). Single cell multi-omics approaches which involves obtaining information from multiple components within a single cell is also gaining significant interest as it allows the assessment of genotype and phenotype relationship in regulating the cell states (Macaulay, Ponting et al. 2017, Liu, Liu et al. 2019).

Nonetheless, most of the single-cell omics analyses does not preserve spatial information as it requires the cells to be isolated from their microenvironment (Yuan, Cai et al. 2017). Another limitation is that a snap-shot analysis is inadequate to evaluate the dynamic nature of cellular processes and therefore lack the details regarding the temporal regulation of the cellular states (Skylaki, Hilsenbeck et al. 2016). Transcriptomic profiling of cells in-situ using fluorescence in-situ hybridization or sequencing will enable the decoding of the spatial regulation of cellular heterogeneity at single-cell resolution (Lee, Daugharthy et al. 2014, Chen, Boettiger et al. 2015, Suva and Tirosh 2019). Single cell RNA sequencing data can be mapped to spatial transcriptomic data using advanced computational methods (Satija, Farrell et al. 2015, Edsgard, Johnsson et al. 2018). Although acquisition techniques have greatly improved, better analysis tools are still lacking. Using a newly developed high-throughput automated single cell image analysis (HASCIA), the spatio-temporal factors regulating glioblastoma stem cell state transitions has been recently investigated (Chumakova, Hitomi et al. 2019). Integrating the transcriptomic and spatial data can significantly improve the interpretation of the CSC plasticity (Satija, Farrell et al. 2015, Yuan, Cai et al. 2017). A recent work coupling large scale single cell-resolution 3D imaging strategy, lineage tracing and RNA sequencing in pTEN/ Trp53 deficient mice models, observed extensive molecular heterogeneity and clonal plasticity within tumors and found that EMT is not a rare event within the tumors (Rios, Capaldo et al. 2019). Live single-cell imaging techniques are also being developed which overcomes the limitation of static snap-shot analyses in studying the temporal regulation of cellular state changes (Fumagalli, Bruens et al. 2019). The number of genes analyzed by such studies are much less than snap-shot studies and the lack of specialized tools and computational methods for handling the large amount of data generated through such studies is a major challenge (Skylaki, Hilsenbeck et al. 2016). 
Single-cell analysis has emerged as a powerful tool over the past few years and has the enormous potential to understand the biology of CSCs. Development of newer tools and analysis methods and integrative approach are required for better comprehending the cell state transitions and improved therapeutic strategies.

\section{Computational methods to identify CSCs}

With the deluge of preclinical and clinical data being generated at a high-dimensional level, computational approaches to extract meaningful information and generate testable hypotheses are becoming more common (Suhail, Cain et al. 2019). Various 'top-down' and 'bottom-up' computational methods provide a framework to unravel novel insights into various aspects of the dynamics of cancer progression such as role of intra-tumoral heterogeneity, dynamics of EMT, CSCs and its role in metastases, evolutionary dynamics of cancer initiation and progression, prediction of treatment response and therapy resistance. While 'top-down' methods use high-dimensional data and apply an inferential metric to identify patterns through machine learning and/or network reconstruction, the 'bottom-up' approaches aim to elucidate the emergent dynamics of a phenomenon based on its mechanism-based description through mathematical modeling. Both approaches can be synergistically used to predict and/or interpret cellular behavior (Altrock, Liu et al. 2015, Jolly, Tripathi et al. 2017).

Mechanism-based, i.e. 'bottom-up', mathematical models have been useful in understanding the dynamics of complex regulatory networks that modulate cancer stem cell behavior such as stem cell state transitions and dedifferentiation (Sehl and Wicha 2018). Recent studies using mathematical models have predicted that cells in one or more hybrid E/M phenotypes are associated more with stemness as compared to cells in purely mesenchymal or purely epithelial (Jolly, Huang et al. 2014). These predictions have since been validated in vitro and in vivo (Grosse-Wilde, Fouquier d'Herouel et al. 2015, Bierie, Pierce et al. 2017, Pastushenko, Brisebarre et al. 2018, Kroger, Afeyan et al. 2019) and has been supported by clinical data (Jolly, Somarelli et al. 2019). How are the pathways of EMT and stemness interconnected with each other? These questions can be addressed by investigating in silico the coupling between core regulatory circuits of EMT, CSCs and other connected signaling pathways such as Notch signaling; this model predicted that altering the coupling strength between EMT and CSC networks and/or modulating Notch signaling can change the position of 'stemness window' on the 'EMT axis', thus generating various subsets of CSCs in terms of EMT phenotypes (Bocci, 
Jolly et al. 2018). Such CSC heterogeneity has been extensively seen across cancers (Liu, Cong et al. 2014, Giraddi, Chung et al. 2018, Zheng, Pomyen et al. 2018). A common unifying principle that has emerged upon investigating the regulatory networks underlying EMT, CSCs and related traits such as drug resistance has been the role of feedback loops in enabling multiple phenotypes (i.e. heterogeneity) and the ability to switch among them (i.e. plasticity) (Huang, Jolly et al. 2015, Mooney, Talebian et al. 2017, Tripathi, Fahrmann et al. 2017, Jolly, Preca et al. 2018, Saha, Kumar et al. 2018).

'Data-based' models have also been valuable in decoding CSC signatures. A stemness index was derived using one-class logistic regression and observed to be higher in the metastatic breast cancer cells compared with primary tumors (Malta, Sokolov et al. 2018), suggesting the possibility of a signature specific to metastatic cancer stem cells. Similar logistic regression models have been used to quantify the extent of EMT (George, Jolly et al. 2017) that has revealed the heterogeneity of EMT phenotypes in various CSCs and their subsets (Bocci, Jolly et al. 2018), hence strengthening the insights from 'mechanism-based' or 'bottom-up' models.

Another set of questions where mathematical models have been useful is estimating the fraction of CSCs in a tumor. Many studies have used population-level models to understand the difference in growth kinetics of CSCs and non-CSCs, and used that to offer a potential mechanistic underpinning of 'tumor growth paradox' i.e. accelerated tumor growth with increased cell death (Hillen, Enderling et al. 2013). Typically, CSC represent a minor cell population within a tumor, major population being the non-CSCs which compete with the CSCs for space and resources. While induction of cell death results into death of bulk of nonCSCs which facilitates increase in CSC division, ultimately resulting into expansion of CSC population and increase in tumor progression (Hillen, Enderling et al. 2013). In contrary, another study showed that the CSC population within a tumor is homeostatically maintained such that reducing CSC population below a threshold triggers extensive phenotypic switching of non-CSC to CSC population (Sellerio, Ciusani et al. 2015). Thus, while the dynamics and mechanisms of CSC generation, plasticity and maintenance remain to be comprehensively understood (Enderling 2015), integrating these different modeling approaches with one another and with experimental and clinical data shall contribute to revealing this complex behavior at an intracellular and at a population level. Such an improved dynamic understanding can help identify optimal treatment strategies to reduce tumor burden, such as a combination of radiation and differentiation therapies (Bachman and Hillen 2013), or a sequential treatment of drugs to 
tackle the de novo generation of CSCs (Gupta, Fillmore et al. 2011) and their functional attributes (Goldman, Majumder et al. 2015).

\section{Spatial organization of CSCs}

Spatial heterogeneity is a fundamental feature of tumor microenvironment (TME) that contains diverse cell types (Yuan 2016, Yuan, Cai et al. 2017). One canonical representation of spatial heterogeneity is the co-occurrence of vascular and hypoxic regions, as observed in solid tumors (Alfarouk, Ibrahim et al. 2013). This heterogeneity can alter cellular phenotypes, for instance, glioblastoma cells in hypoxic regions have been shown to over-express epidermal growth factor receptor (EGFR) while those over-expressing platelet-derived growth factor receptor (PDGFRA) were enriched in vascular regions (Little, Popov et al. 2012). Similarly, hypoxic TME induced by antiangiogenic agents can increase breast cancer stem cells (Conley, Gheordunescu et al. 2012). Thus, spatial heterogeneity of TME can give rise to differential spatial organization of cancer sub-populations within a tumor.

Indeed, varying levels of nuclear beta-catenin expression was observed in different subpopulations of well-differentiated colorectal cancer, suggested to be regulated by TME (Brabletz, Jung et al. 2001). Cells in the invasive front of the primary tumor as well as metastases expressed high levels of nuclear beta-catenin, and lacked the expression of membranous E-cadherin, indicative of an epithelial-mesenchymal transition (EMT). On the other hand, centrally located cells in the primary tumor and metastases showed cytoplasmic beta-catenin and membranous E-cadherin expression, perhaps due to a mesenchymal-epithelial transition (MET). These two transient phenotypic transitions could by driven by specific TME present in the invasive front and central regions of the tumor by modulating expression of intracellular beta-catenin (Brabletz, Jung et al. 2001). Consistently, the CD24-CD44+ mesenchymal breast CSCs (BCSCs) were found in the invasive edge of the tumor, while the more epithelial or hybrid E/M CSCs, identified by ALDH1+, were localized in the interior regions of the tumor (Liu, Cong et al. 2014). In vitro, these two subpopulations, when segregated, could give rise to the other and other non-CSCs; however multiple studies consistently report spatial heterogeneity with respect to EMT in a primary tumor (Jung, Schrauder et al. 2001, Schmalhofer, Brabletz et al. 2009, Bronsert, Enderle-Ammour et al. 2014, Liu, Cong et al. 2014, Grigore, Jolly et al. 2016). Therefore, put together, these observations beg the question of what mechanisms might underlie such patterning. 
Recent efforts have attempted to elucidate the mechanisms underlying such spatial heterogeneity. A mathematical modeling analysis revealed that in the presence of a gradient of TGF- $\beta$ (EMT inducing) signal, cell-cell communication among tumor cells mediated via Notch-Jagged signaling can recapitulate the experimentally observed spatial organization of CSCs sub-populations with varying EMT phenotypes (Bocci, Gearhart-Serna et al. 2019). Notch-Jagged signaling can be promoted by inflammatory cytokines like IL-6 which can stabilize hybrid E/M phenotype and increase the spatial proximity of hybrid E/M CSCs. In vitro knock down of JAG1 in SUM149 human breast cancer cells significantly reduced their tumor organoid formation, confirming the role of Notch-Jagged signaling in tumor progression (Bocci, Gearhart-Serna et al. 2019). Future studies can focus on gaining a understanding of other interconnected aspects of heterogeneity in TME.

Spatial heterogeneity of tumors can be used as a predictor of cancer prognosis and treatment response across different cancer types (Yuan 2016). For example, colorectal cancer patients with high density of tumor infiltrating lymphocytes responded to anti-cancer therapy (Gong, Anders et al. 2018). Spatial heterogeneity can also significantly impact the time to occurrence in cancer cells exposed to continuous as well as adaptive therapies (Gallaher, Enriquez-Navas et al. 2018). Thus, the spatiotemporal dynamics of phenotypic changes induced by TME can be pivotal in aggravating aspects of tumor progression.

\section{Mechanisms controlling CSC plasticity}

CSC plasticity is controlled by both cell-intrinsic and cell-extrinsic factors (Poli, Fagnocchi et al. 2018). Several studies have implied the importance of key transcription factors in modulating the generation of CSCs and regulation of cellular plasticity (Eun, Ham et al. 2017). The transcription factors like OCT3/4, SOX2, NANOG, KLF4 has been found to induce reprogramming of somatic cells into pluripotent stem cell [induced pluripotent stem cells (iPSC)] (Liu, Yu et al. 2013). A plethora of research has shown the expression of iPSC transcription factors in CSCs of many cancers that contribute to tumor progression (Gu, Yuan et al. 2007, Ben-Porath, Thomson et al. 2008, Liu, Yu et al. 2013). For example, the introduction of OCT3/4, NANOG and KLF4 retrovirally into human colon cancer cells resulted in enhanced CSC properties and the xenografts of these cells actually resembled the original human tumor tissue (Oshima, Yamada et al. 2014). Similarly, in glioblastoma, Suva et al., identified a core set of neurodevelopmental transcription factors (POU3F2, SOX2, SALL2, 
and OLIG2) that were sufficient to reprogram differentiated glioblastoma cells to CSCs (Suva, Rheinbay et al. 2014). Tumor suppressor transcription factors like p53, pTEN has also been associated with CSC plasticity (Cabrera, Hollingsworth et al. 2015, da Silva-Diz, LorenzoSanz et al. 2018, Santoro, Vlachou et al. 2019). Loss of p53 lead to increased expression of Nestin and enable the dedifferentiation of hepatocytes and thereby contributes to cellular plasticity in liver carcinogenesis (Tschaharganeh, Xue et al. 2014). Combined loss of p53/ pTEN in clonal prostate epithelial cells caused transformation of multipotent progenitors and lead to epithelial to mesenchymal transition (Martin, Liu et al. 2011). Genetic mutations of oncogene like KRAS and tumor suppressor like APC is also linked to the generation of stemlike cells (Easwaran, Tsai et al. 2014).

Many studies have pointed out various mechanisms of epigenetic regulation such as bivalent chromatin state, DNA methylation, histone modifications in mediating CSC plasticity (Poli, Fagnocchi et al. 2018). For example, in basal like breast cancer cells, Chaffer and colleagues observed that Zeb1 promoter of non-CSCs are maintained in a bivalent configuration and in response to TGF $\beta$, the chromatin switches to an active state leading to the transcription of Zeb1, consequently converting the non-CSCs to CSCs (Chaffer, Marjanovic et al. 2013). Homeobox genes are master regulators of development and maintains the balance between proliferation and differentiation. A study by Shah et al., has shown that a loss of function of HoxC8, a homeobox gene, in non-tumorigenic mammary epithelial cells due to promoter DNA hypermethylation is associated with the expansion of CSC pool, increased self-renewal and a transformed phenotype (Shah, Cardenas et al. 2017). A histone modifier, enhancer of zeste homolog $2(\mathrm{EZH} 2)$ is a core member of polycomb repressor complex 2 (PRC2) and mediates transcriptional repression of target genes via trimethylation of lysine 27 of histone 3 (H3K27me3) (Gan, Yang et al. 2018). EZH2 is upregulated in many cancers and its enhanced expression of EZH2 is associated with invasion, migration and stemness (Yamaguchi and Hung 2014). In breast cancer, overexpression of EZH2 has increased mammosphere formation and self-renewal ability in breast CSCs (Chang, Yang et al. 2011, Wen, Cai et al. 2017). In glioblastoma, loss of $\mathrm{H} 3 \mathrm{~K} 27 \mathrm{me} 3$ leads to aberrant activation of a transcription factor, ASCL1 and results in Wnt activation which is required for tumorigenicity and CSC maintenance (Rheinbay, Suva et al. 2013). On the other hand, in pediatric glioblastomas, the mutations in histone variants $\mathrm{H} 3.1$ and $\mathrm{H} 3.3$ results in reduced activity of EZH2 and consequently reprograms towards a stem cell-like state (Lewis, Muller et al. 2013). Another histone modifier, JARID1B, a histone demethylase is associated with CSC plasticity in melanoma (Roesch, 
Fukunaga-Kalabis et al. 2010). These observations suggest that CSCs hijack and exploit the reversible nature of epigenetic modifications to achieve their plastic nature (Wainwright and Scaffidi 2017). However, this reversibility also offers an attractive opportunity that needs to be harnessed for therapeutic targeting.

\section{CSC plasticity and EMT}

EMT is a reversible dynamic process which is critical during embryonic development and also aberrantly activated during various pathological processes like wound healing, fibrosis and cancer progression (Kalluri and Weinberg 2009, Jolly, Ward et al. 2018). EMT is characterized by the loss of apico-basal polarity, rearrangements in the cytoskeleton and the acquisition of mesenchymal gene expression signature (Kalluri and Weinberg 2009). The activation of EMT program is associated with the acquisition of stem like characteristics and has been implicated in different cancers (Mani, Guo et al. 2008, Shibue and Weinberg 2017, Singla, Kumar et al. 2018, Dongre and Weinberg 2019). Initial reports suggested that activation of an EMT program endowed cells with traits similar to CSCs, such as enhanced colony formation in vitro and enhanced tumorigenesis in vivo (Shibue and Weinberg 2017). Recent studies have, however, presented a more nuanced understanding of the interconnection between EMT and CSCs. Cells that undergo a more extreme version of EMT can lose the stemness gained during the initiation of EMT; thus, cells in a hybrid epithelial/ mesenchymal phenotype are much more likely to be stem-like as compared to those on either end of the spectrum - pure epithelial or pure mesenchymal (Bierie, Pierce et al. 2017, Jolly, Mani et al. 2018). A recent study by Kroger et al., has found that the acquisition of a hybrid phenotype a critical for the maintenance of tumorigenicity of basal breast cancer cells. Based on CD104/CD44 cell surface antigen expression and by regulating the expression of transcription factors like Zeb1 and Snail, they isolated highly tumorigenic cell population residing stably in a hybrid EMT state. This hybrid E/M cell population showed enhanced stemness which was mediated by increased expression of Snail and Wnt signaling pathway (Kroger, Afeyan et al. 2019). Another interesting study by Pastushenko et al., looked at the spectrum of EMT states that exist in a tumor rather than the binary fixed state that was accepted for long. The hybrid E/M tumor cells were associated with differences in their transcriptional and epigenetic programs, metastatic potential and also the location within a tumor (Pastushenko, Brisebarre et al. 2018). It would be interesting to further understand whether these different hybrid states also respond differently to cues like chemotherapeutic treatment leading to resistance and ultimately relapse in cancer patients. 


\section{The effect of the tumor microenvironment on CSC plasticity}

The tumor microenvironment is a complex and dynamic ecosystem consisting of diverse stromal cell types like fibroblasts, endothelial cells, adipocytes and immune cells which are influenced by the cancer cells and vice versa. In addition to the juxtacrine crosstalk with each other and cancer cells through direct cell to cell contacts, there are also factors secreted by the different cell types that form complex interacting networks which ultimately contribute to tumor growth and metastasis (Swartz, Iida et al. 2012, Quail and Joyce 2013, Peltanova, Raudenska et al. 2019). Accumulating evidence suggests that crosstalk with the stromal cells have significant implications on the stem-like behaviour and phenotypic plasticity of cancer cells (Pattabiraman and Weinberg 2014, Cabrera, Hollingsworth et al. 2015, Prasetyanti and Medema 2017). Cancer associated fibroblasts (CAFs) are a major component of the tumor microenvironment and play a pivotal role in various aspects of tumor progression (Kwa, Herum et al. 2019). CAFs were found to modulate the stem cell plasticity in hepatocellular carcinoma through c-Met/FRA1/HEY1 signaling (Lau, Lo et al. 2016), in pancreatic adenocarcinoma through FAK signaling through direct interactions mediated by collagen (Begum, McMillan et al. 2019) and regulate lung cancer stem cell plasticity by IGF-II/IGF1R signaling pathway (Chen, Ho et al. 2014). In a recent study, the extent of intracellular Notch1 signalling in mesenchymal stem cell-derived dermal fibroblasts was found to determine the ability of these cells to regulate melanoma aggressiveness, stemness and phenotypic plasticity (Du, Shao et al. 2019). Another key component is the immune system which plays a crucial role in regulating CSC plasticity. In response to chemotherapy, macrophages can secrete factor like OncostatinM (OSM), an IL-6 family cytokine which in turn can activate the dedifferentiation of triple negative breast cancer cells into aggressive stem cells (Doherty, Parvani et al. 2019) and this could be mediated through co-operative STAT3/SMAD3 signaling (Junk, Bryson et al. 2017). OSM can also be secreted by cancer associated adipocytes which can also promote stemness(Wolfson, Eades et al. 2015).

The physical and chemical composition of the microenvironment like acidic $\mathrm{pH}$, low oxygen and nutrient availability, rigidity and porosity of the ECM also play an important role in regulating the cancer stem cell behaviour (Hjelmeland, Wu et al. 2011, Nallanthighal, Heiserman et al. 2019, Prager, Xie et al. 2019). A classic example would be hypoxia which is a hallmark of tumor progression in solid tumors and is associated with metastasis, therapeutic 
resistance and poor survival (Lequeux, Noman et al. 2019). A hypoxic microenvironment is known to regulate various aspects of malignant progression including cellular plasticity. In Glioblastoma, hypoxia was found to promote self-renewal in non-stem cells by upregulating important factors like OCT4, NANOG and cMYC (Heddleston, Li et al. 2009). Also, the hypoxic microenvironment can select the fate of breast cancer stem cells in vivo as shown by Kim et al (Kim, Lin et al. 2018). Using flow cytometry, hypoxic and non-hypoxic breast cancer cells were isolated from hypoxia sensing xenografts of MDA-MB-231 and MCF7 breast cancer cell lines. Hypoxic tumor cells showed enhanced cancer stem cell characteristics compared to non-hypoxic cells which is attributed to the PI3K/AKT signaling. Interestingly, this differential cell fate was observed only in tumor cells isolated from hypoxic tumor microenvironment in vivo and not in tumor cells treated by hypoxia in vitro alone (Kim, Lin et al. 2018).

These studies underscore the importance of the microenvironment in sculpting intra-tumoral heterogeneity and CSC plasticity and highlight the need to better understand the tumormicroenvironment crosstalk for the development of effective therapeutic strategies. However, it is still controversial whether the CSC heterogeneity arises as a consequence of the microenvironment exerted selection pressure or whether plasticity is an intrinsic, default feature of the cancer cells that enable to adapt to varying cues from the microenvironment (Poli, Fagnocchi et al. 2018, Dirkse, Golebiewska et al. 2019). Recent evidence from the study on glioblastoma, suggests that intrinsic plasticity of tumor cells enables them to stochastically transition between different states defined by distinct expression of cancer stem cell markers and adapt to the microenvironment. Although all cell subpopulations are capable of phenotypic adjustment, they vary in their speed of adaptation (Dirkse, Golebiewska et al. 2019).

\section{Discussion/Conclusion}

The issue of phenotypic plasticity presents a clear and present danger in the treatment of cancer patients. Accumulating evidence suggests that CSCs consist of different sub-populations that can interconvert among different states through intracellular and intercellular regulatory networks. Over expression of one or more transcription factors or activating transdifferentiation processes such as EMT can drive the switch among CSCs and non-CSCs as well as between different subsets of CSCs. These adaptive strategies adopted by cells must be taken into account while devising new therapeutic strategies in the clinic in order to target all populations effectively. 
The challenges to addressing this issue are multifold. The ability to identify the plastic CSC population using markers has its inherent problems which are further confounded by each individual patient's unique biochemical and biomechanical signatures. The general consensus is that drug resistance is achieved through a transition to a slow cycling state which is reversible once the stress is removed. Understanding how the cells switch from a slow cycling state and reenter the proliferative phase of the cell cycle will be key to targeting this population which contributes to minimal residual disease.

Using latest developments in computational and experimental methods will allow us to map the different states of tumor cells within multiple locations in a tumor, thus enabling a more comprehensive view of the genetic and non-genetic heterogeneity that exists within a cancer. Correlating such intratumoral heterogeneity with cellular phenotypes will be key to devising better therapeutic options in patients to ablate the tumor cells stably within a patient.

\section{Author contributions}

$\mathrm{RN}$ and MKJ designed the review. AT, KS, RM, MJ and RN wrote, read and approved of the manuscript.

\section{Funding}

$\mathrm{RN}$ is the recipient of the Ramanujan Fellowship from the Government of India (SERB) (SB/S2/RJN/182/2014). MKJ was supported by Ramanujan Fellowship (SB/S2/RJN049/2018) provided by SERB, DST, Government of India. AT was supported by CSIR-Junior research fellowship.

\section{Conflicts of Interest}

The authors declare that the research was conducted in the absence of any commercial or financial relationships that could be construed as a potential conflict of interest. 


\section{References}

Agliano, A., A. Calvo and C. Box (2017). "The challenge of targeting cancer stem cells to halt metastasis." Semin Cancer Biol 44: 25-42.

Akgul, S., A. M. Patch, R. C. J. D'Souza, P. Mukhopadhyay, K. Nones, S. Kempe, S. H. Kazakoff, R. L. Jeffree, B. W. Stringer, J. V. Pearson, N. Waddell and B. W. Day (2019). "Intratumoural Heterogeneity Underlies Distinct Therapy Responses and Treatment Resistance in Glioblastoma." Cancers (Basel) 11(2).

Akrap, N., D. Andersson, E. Bom, P. Gregersson, A. Stahlberg and G. Landberg (2016). "Identification of Distinct Breast Cancer Stem Cell Populations Based on Single-Cell Analyses of Functionally Enriched Stem and Progenitor Pools." Stem Cell Reports 6(1): 121-136.

Alfarouk, K. O., M. E. Ibrahim, R. A. Gatenby and J. S. Brown (2013). "Riparian ecosystems in human cancers." Evol Appl 6(1): 46-53.

Altrock, P. M., L. L. Liu and F. Michor (2015). "The mathematics of cancer: integrating quantitative models." Nat Rev Cancer 15(12): 730-745.

Aponte, P. M. and A. Caicedo (2017). "Stemness in Cancer: Stem Cells, Cancer Stem Cells, and Their Microenvironment." Stem Cells Int 2017: 5619472.

Babahosseini, H., A. N. Ketene, E. M. Schmelz, P. C. Roberts and M. Agah (2014). "Biomechanical profile of cancer stem-like/tumor-initiating cells derived from a progressive ovarian cancer model." Nanomedicine 10(5): 1013-1019.

Bachman, J. W. and T. Hillen (2013). "Mathematical optimization of the combination of radiation and differentiation therapies for cancer." Front Oncol 3: 52.

Begum, A., R. H. McMillan, Y. T. Chang, V. R. Penchev, N. V. Rajeshkumar, A. Maitra, M. G. Goggins, J. R. Eshelman, C. L. Wolfgang, Z. A. Rasheed and W. Matsui (2019). "Direct Interactions With Cancer-Associated Fibroblasts Lead to Enhanced Pancreatic Cancer Stem Cell Function." Pancreas 48(3): 329-334.

Ben-Porath, I., M. W. Thomson, V. J. Carey, R. Ge, G. W. Bell, A. Regev and R. A. Weinberg (2008). "An embryonic stem cell-like gene expression signature in poorly differentiated aggressive human tumors." Nat Genet 40(5): 499-507.

Bhatia, S., J. Monkman, T. Blick, C. Pinto, M. Waltham, S. H. Nagaraj and E. W. Thompson (2019). "Interrogation of Phenotypic Plasticity between Epithelial and Mesenchymal States in Breast Cancer." J Clin Med 8(6).

Biddle, A., L. Gammon, X. Liang, D. E. Costea and I. C. Mackenzie (2016). "Phenotypic Plasticity Determines Cancer Stem Cell Therapeutic Resistance in Oral Squamous Cell Carcinoma." EBioMedicine 4: 138-145.

Bierie, B., S. E. Pierce, C. Kroeger, D. G. Stover, D. R. Pattabiraman, P. Thiru, J. Liu Donaher, F. Reinhardt, C. L. Chaffer, Z. Keckesova and R. A. Weinberg (2017). "Integrin-beta4 identifies cancer stem cell-enriched populations of partially mesenchymal carcinoma cells." Proc Natl Acad Sci U S A 114(12): E2337-E2346.

Bocci, F., L. Gearhart-Serna, M. Boareto, M. Ribeiro, E. Ben-Jacob, G. R. Devi, H. Levine, J. N. Onuchic and M. K. Jolly (2019). "Toward understanding cancer stem cell heterogeneity in the tumor microenvironment." Proc Natl Acad Sci U S A 116(1): 148-157.

Bocci, F., M. K. Jolly, J. T. George, H. Levine and J. N. Onuchic (2018). "A mechanism-based computational model to capture the interconnections among epithelial-mesenchymal transition, cancer stem cells and Notch-Jagged signaling." Oncotarget 9(52): 29906-29920.

Bongiorno, T., J. Gura, P. Talwar, D. Chambers, K. M. Young, D. Arafat, G. Wang, E. L. JacksonHolmes, P. Qiu, T. C. McDevitt and T. Sulchek (2018). "Biophysical subsets of embryonic stem cells display distinct phenotypic and morphological signatures." PLoS One 13(3): e0192631.

Brabletz, T., A. Jung, S. Reu, M. Porzner, F. Hlubek, L. A. Kunz-Schughart, R. Knuechel and T. Kirchner (2001). "Variable beta-catenin expression in colorectal cancers indicates tumor progression driven by the tumor environment." Proc Natl Acad Sci U S A 98(18): 10356-10361. 
Broders-Bondon, F., T. H. Nguyen Ho-Bouldoires, M. E. Fernandez-Sanchez and E. Farge (2018). "Mechanotransduction in tumor progression: The dark side of the force." J Cell Biol 217(5): 1571-1587. Bronsert, P., K. Enderle-Ammour, M. Bader, S. Timme, M. Kuehs, A. Csanadi, G. Kayser, I. Kohler, D. Bausch, J. Hoeppner, U. T. Hopt, T. Keck, E. Stickeler, B. Passlick, O. Schilling, C. P. Reiss, Y. Vashist, T. Brabletz, J. Berger, J. Lotz, J. Olesch, M. Werner and U. F. Wellner (2014). "Cancer cell invasion and EMT marker expression: a three-dimensional study of the human cancer-host interface." J Pathol 234(3): 410-422.

Byun, S., S. Son, D. Amodei, N. Cermak, J. Shaw, J. H. Kang, V. C. Hecht, M. M. Winslow, T. Jacks, P. Mallick and S. R. Manalis (2013). "Characterizing deformability and surface friction of cancer cells." Proc Natl Acad Sci U S A 110(19): 7580-7585.

Cabrera, M. C., R. E. Hollingsworth and E. M. Hurt (2015). "Cancer stem cell plasticity and tumor hierarchy." World J Stem Cells 7(1): 27-36.

Celia-Terrassa, T. and M. K. Jolly (2019). "Cancer Stem Cells and Epithelial-to-Mesenchymal Transition in Cancer Metastasis." Cold Spring Harb Perspect Med.

Chaffer, C. L., I. Brueckmann, C. Scheel, A. J. Kaestli, P. A. Wiggins, L. O. Rodrigues, M. Brooks, F. Reinhardt, Y. Su, K. Polyak, L. M. Arendt, C. Kuperwasser, B. Bierie and R. A. Weinberg (2011). "Normal and neoplastic nonstem cells can spontaneously convert to a stem-like state." Proc Natl Acad Sci U S A 108(19): 7950-7955.

Chaffer, C. L., N. D. Marjanovic, T. Lee, G. Bell, C. G. Kleer, F. Reinhardt, A. C. D'Alessio, R. A. Young and R. A. Weinberg (2013). "Poised chromatin at the ZEB1 promoter enables breast cancer cell plasticity and enhances tumorigenicity." Cell 154(1): 61-74.

Chang, C. J., J. Y. Yang, W. Xia, C. T. Chen, X. Xie, C. H. Chao, W. A. Woodward, J. M. Hsu, G. N. Hortobagyi and M. C. Hung (2011). "EZH2 promotes expansion of breast tumor initiating cells through activation of RAF1-beta-catenin signaling." Cancer Cell 19(1): 86-100.

Chen, J. and S. Kumar (2017). "Biophysical Regulation of Cancer Stem/Initiating Cells: Implications for Disease Mechanisms and Translation." Curr Opin Biomed Eng 1: 87-95.

Chen, J., W. Zhou, Q. Jia, J. Chen, S. Zhang, W. Yao, F. Wei, Y. Zhang, F. Yang, W. Huang, Y. Zhang, H. Zhang, Y. Zhang, B. Huang, Z. Zhang, H. Jia and N. Wang (2016). "Efficient extravasation of tumorrepopulating cells depends on cell deformability." Sci Rep 6: 19304.

Chen, K., Y. H. Huang and J. L. Chen (2013). "Understanding and targeting cancer stem cells: therapeutic implications and challenges." Acta Pharmacol Sin 34(6): 732-740.

Chen, K. H., A. N. Boettiger, J. R. Moffitt, S. Wang and X. Zhuang (2015). "RNA imaging. Spatially resolved, highly multiplexed RNA profiling in single cells." Science 348(6233): aaa6090.

Chen, W., S. G. Allen, W. Qian, Z. Peng, S. Han, X. Li, Y. Sun, C. Fournier, L. Bao, R. H. W. Lam, S. D. Merajver and J. Fu (2019). "Biophysical Phenotyping and Modulation of ALDH+ Inflammatory Breast Cancer Stem-Like Cells." Small 15(5): e1802891.

Chen, W., J. Dong, J. Haiech, M. C. Kilhoffer and M. Zeniou (2016). "Cancer Stem Cell Quiescence and Plasticity as Major Challenges in Cancer Therapy." Stem Cells Int 2016: 1740936.

Chen, W. J., C. C. Ho, Y. L. Chang, H. Y. Chen, C. A. Lin, T. Y. Ling, S. L. Yu, S. S. Yuan, Y. J. Chen, C. Y. Lin, S. H. Pan, H. Y. Chou, Y. J. Chen, G. C. Chang, W. C. Chu, Y. M. Lee, J. Y. Lee, P. J. Lee, K. C. Li, H. W. Chen and P. C. Yang (2014). "Cancer-associated fibroblasts regulate the plasticity of lung cancer stemness via paracrine signalling." Nat Commun 5: 3472.

Chumakova, A. P., M. Hitomi, E. P. Sulman and J. D. Lathia (2019). "High-Throughput Automated Single-Cell Imaging Analysis Reveals Dynamics of Glioblastoma Stem Cell Population During State Transition." Cytometry A 95(3): 290-301.

Conley, S. J., E. Gheordunescu, P. Kakarala, B. Newman, H. Korkaya, A. N. Heath, S. G. Clouthier and M. S. Wicha (2012). "Antiangiogenic agents increase breast cancer stem cells via the generation of tumor hypoxia." Proc Natl Acad Sci U S A 109(8): 2784-2789.

da Silva-Diz, V., L. Lorenzo-Sanz, A. Bernat-Peguera, M. Lopez-Cerda and P. Munoz (2018). "Cancer cell plasticity: Impact on tumor progression and therapy response." Semin Cancer Biol 53: 48-58.

Dagogo-Jack, I. and A. T. Shaw (2018). "Tumour heterogeneity and resistance to cancer therapies." Nat Rev Clin Oncol 15(2): 81-94.

de Sousa e Melo, F., A. V. Kurtova, J. M. Harnoss, N. Kljavin, J. D. Hoeck, J. Hung, J. E. Anderson, E. E. Storm, Z. Modrusan, H. Koeppen, G. J. Dijkgraaf, R. Piskol and F. J. de Sauvage (2017). "A 
distinct role for Lgr5(+) stem cells in primary and metastatic colon cancer." Nature 543(7647): 676680 .

Dirkse, A., A. Golebiewska, T. Buder, P. V. Nazarov, A. Muller, S. Poovathingal, N. H. C. Brons, S. Leite, N. Sauvageot, D. Sarkisjan, M. Seyfrid, S. Fritah, D. Stieber, A. Michelucci, F. Hertel, C. HeroldMende, F. Azuaje, A. Skupin, R. Bjerkvig, A. Deutsch, A. Voss-Bohme and S. P. Niclou (2019). "Stem cell-associated heterogeneity in Glioblastoma results from intrinsic tumor plasticity shaped by the microenvironment." Nat Commun 10(1): 1787.

Doherty, M. R., J. G. Parvani, I. Tamagno, D. J. Junk, B. L. Bryson, H. J. Cheon, G. R. Stark and M. W. Jackson (2019). "The opposing effects of interferon-beta and oncostatin-M as regulators of cancer stem cell plasticity in triple-negative breast cancer." Breast Cancer Res 21(1): 54.

Doherty, M. R., J. M. Smigiel, D. J. Junk and M. W. Jackson (2016). "Cancer Stem Cell Plasticity Drives Therapeutic Resistance." Cancers (Basel) 8(1).

Dongre, A. and R. A. Weinberg (2019). "New insights into the mechanisms of epithelial-mesenchymal transition and implications for cancer." Nat Rev Mol Cell Biol 20(2): 69-84.

Du, Y., H. Shao, M. Moller, R. Prokupets, Y. T. Tse and Z. J. Liu (2019). "Intracellular Notch1 Signaling in Cancer-Associated Fibroblasts Dictates the Plasticity and Stemness of Melanoma Stem/Initiating Cells." Stem Cells 37(7): 865-875.

Easwaran, H., H. C. Tsai and S. B. Baylin (2014). "Cancer epigenetics: tumor heterogeneity, plasticity

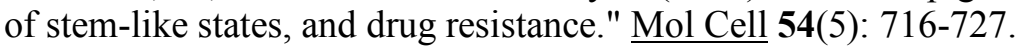

Edsgard, D., P. Johnsson and R. Sandberg (2018). "Identification of spatial expression trends in singlecell gene expression data." Nat Methods 15(5): 339-342.

Eirew, P., A. Steif, J. Khattra, G. Ha, D. Yap, H. Farahani, K. Gelmon, S. Chia, C. Mar, A. Wan, E. Laks, J. Biele, K. Shumansky, J. Rosner, A. McPherson, C. Nielsen, A. J. Roth, C. Lefebvre, A. Bashashati, C. de Souza, C. Siu, R. Aniba, J. Brimhall, A. Oloumi, T. Osako, A. Bruna, J. L. Sandoval, T. Algara, W. Greenwood, K. Leung, H. Cheng, H. Xue, Y. Wang, D. Lin, A. J. Mungall, R. Moore, Y. Zhao, J. Lorette, L. Nguyen, D. Huntsman, C. J. Eaves, C. Hansen, M. A. Marra, C. Caldas, S. P. Shah and S. Aparicio (2015). "Dynamics of genomic clones in breast cancer patient xenografts at singlecell resolution." Nature 518(7539): 422-426.

Enderling, H. (2015). "Cancer stem cells: small subpopulation or evolving fraction?" Integr Biol (Camb) 7(1): 14-23.

Etzrodt, M., M. Endele and T. Schroeder (2014). "Quantitative single-cell approaches to stem cell research." Cell Stem Cell 15(5): 546-558.

Eun, K., S. W. Ham and H. Kim (2017). "Cancer stem cell heterogeneity: origin and new perspectives on CSC targeting." BMB Rep 50(3): 117-125.

Fernandez-Cortes, M., D. Delgado-Bellido and F. J. Oliver (2019). "Vasculogenic Mimicry: Become an Endothelial Cell "But Not So Much"." Front Oncol 9: 803.

Fumagalli, A., L. Bruens, C. Scheele and J. van Rheenen (2019). "Capturing Stem Cell Behavior Using Intravital and Live Cell Microscopy." Cold Spring Harb Perspect Biol.

Gallaher, J. A., P. M. Enriquez-Navas, K. A. Luddy, R. A. Gatenby and A. R. A. Anderson (2018). "Spatial Heterogeneity and Evolutionary Dynamics Modulate Time to Recurrence in Continuous and Adaptive Cancer Therapies." Cancer Res 78(8): 2127-2139.

Gan, L., Y. Yang, Q. Li, Y. Feng, T. Liu and W. Guo (2018). "Epigenetic regulation of cancer progression by EZH2: from biological insights to therapeutic potential." Biomark Res 6: 10.

George, J. T., M. K. Jolly, S. Xu, J. A. Somarelli and H. Levine (2017). "Survival Outcomes in Cancer Patients Predicted by a Partial EMT Gene Expression Scoring Metric." Cancer Res 77(22): 6415-6428. Giraddi, R. R., C. Y. Chung, R. E. Heinz, O. Balcioglu, M. Novotny, C. L. Trejo, C. Dravis, B. M. Hagos, E. M. Mehrabad, L. W. Rodewald, J. Y. Hwang, C. Fan, R. Lasken, K. E. Varley, C. M. Perou, G. M. Wahl and B. T. Spike (2018). "Single-Cell Transcriptomes Distinguish Stem Cell State Changes and Lineage Specification Programs in Early Mammary Gland Development." Cell Rep 24(6): 16531666 e1657.

Goldman, A., B. Majumder, A. Dhawan, S. Ravi, D. Goldman, M. Kohandel, P. K. Majumder and S. Sengupta (2015). "Temporally sequenced anticancer drugs overcome adaptive resistance by targeting a vulnerable chemotherapy-induced phenotypic transition." Nature Communications 6(1): 6139. 
Gong, C., R. A. Anders, Q. Zhu, J. M. Taube, B. Green, W. Cheng, I. H. Bartelink, P. Vicini, B. Wang and A. S. Popel (2018). "Quantitative Characterization of CD8+ T Cell Clustering and Spatial Heterogeneity in Solid Tumors." Front Oncol 8: 649.

Gossett, D. R., H. T. Tse, S. A. Lee, Y. Ying, A. G. Lindgren, O. O. Yang, J. Rao, A. T. Clark and D. Di Carlo (2012). "Hydrodynamic stretching of single cells for large population mechanical phenotyping." Proc Natl Acad Sci U S A 109(20): 7630-7635.

Greve, B., R. Kelsch, K. Spaniol, H. T. Eich and M. Gotte (2012). "Flow cytometry in cancer stem cell analysis and separation." Cytometry A 81(4): 284-293.

Grigore, A. D., M. K. Jolly, D. Jia, M. C. Farach-Carson and H. Levine (2016). "Tumor Budding: The Name is EMT. Partial EMT." J Clin Med 5(5).

Grosse-Wilde, A., A. Fouquier d'Herouel, E. McIntosh, G. Ertaylan, A. Skupin, R. E. Kuestner, A. del Sol, K. A. Walters and S. Huang (2015). "Stemness of the hybrid Epithelial/Mesenchymal State in Breast Cancer and Its Association with Poor Survival." PLoS One 10(5): e0126522.

Gu, G., J. Yuan, M. Wills and S. Kasper (2007). "Prostate cancer cells with stem cell characteristics reconstitute the original human tumor in vivo." Cancer Res 67(10): 4807-4815.

Gupta, P. B., C. M. Fillmore, G. Jiang, S. D. Shapira, K. Tao, C. Kuperwasser and E. S. Lander (2011). "Stochastic state transitions give rise to phenotypic equilibrium in populations of cancer cells." Cell 146(4): 633-644.

Gupta, P. B., I. Pastushenko, A. Skibinski, C. Blanpain and C. Kuperwasser (2019). "Phenotypic Plasticity: Driver of Cancer Initiation, Progression, and Therapy Resistance." Cell Stem Cell 24(1): 6578.

Heddleston, J. M., Z. Li, R. E. McLendon, A. B. Hjelmeland and J. N. Rich (2009). "The hypoxic microenvironment maintains glioblastoma stem cells and promotes reprogramming towards a cancer stem cell phenotype." Cell Cycle 8(20): 3274-3284.

Hillen, T., H. Enderling and P. Hahnfeldt (2013). "The tumor growth paradox and immune systemmediated selection for cancer stem cells." Bull Math Biol 75(1): 161-184.

Hjelmeland, A. B., Q. Wu, J. M. Heddleston, G. S. Choudhary, J. MacSwords, J. D. Lathia, R. McLendon, D. Lindner, A. Sloan and J. N. Rich (2011). "Acidic stress promotes a glioma stem cell phenotype." Cell Death Differ 18(5): 829-840.

Hou, Y., H. Guo, C. Cao, X. Li, B. Hu, P. Zhu, X. Wu, L. Wen, F. Tang, Y. Huang and J. Peng (2016). "Single-cell triple omics sequencing reveals genetic, epigenetic, and transcriptomic heterogeneity in hepatocellular carcinomas." Cell Res 26(3): 304-319.

Huang, B., M. K. Jolly, M. Lu, I. Tsarfaty, E. Ben-Jacob and J. N. Onuchic (2015). "Modeling the Transitions between Collective and Solitary Migration Phenotypes in Cancer Metastasis." Sci Rep 5: 17379.

Iliopoulos, D., H. A. Hirsch, G. Wang and K. Struhl (2011). "Inducible formation of breast cancer stem cells and their dynamic equilibrium with non-stem cancer cells via IL6 secretion." Proc Natl Acad Sci U S A 108(4): 1397-1402.

Jaggupilli, A. and E. Elkord (2012). "Significance of CD44 and CD24 as cancer stem cell markers: an enduring ambiguity." Clin Dev Immunol 2012: 708036.

Januskeviciene, I. and V. Petrikaite (2019). "Heterogeneity of breast cancer: The importance of interaction between different tumor cell populations." Life Sci 239: 117009.

Jia, D., M. K. Jolly, S. C. Tripathi, P. Den Hollander, B. Huang, M. Lu, M. Celiktas, E. Ramirez-Pena, E. Ben-Jacob, J. N. Onuchic, S. M. Hanash, S. A. Mani and H. Levine (2017). "Distinguishing mechanisms underlying EMT tristability." Cancer Converg 1(1): 2.

Jolly, M. K., B. Huang, M. Lu, S. A. Mani, H. Levine and E. Ben-Jacob (2014). "Towards elucidating the connection between epithelial-mesenchymal transitions and stemness." J R Soc Interface 11(101): 20140962.

Jolly, M. K., P. Kulkarni, K. Weninger, J. Orban and H. Levine (2018). "Phenotypic Plasticity, BetHedging, and Androgen Independence in Prostate Cancer: Role of Non-Genetic Heterogeneity." Front Oncol 8: 50.

Jolly, M. K., S. A. Mani and H. Levine (2018). "Hybrid epithelial/mesenchymal phenotype(s): The 'fittest' for metastasis?" Biochim Biophys Acta Rev Cancer 1870(2): 151-157. 
Jolly, M. K., B. T. Preca, S. C. Tripathi, D. Jia, J. T. George, S. M. Hanash, T. Brabletz, M. P. Stemmler, J. Maurer and H. Levine (2018). "Interconnected feedback loops among ESRP1, HAS2, and CD44 regulate epithelial-mesenchymal plasticity in cancer." APL Bioeng 2(3): 031908.

Jolly, M. K., J. A. Somarelli, M. Sheth, A. Biddle, S. C. Tripathi, A. J. Armstrong, S. M. Hanash, S. A. Bapat, A. Rangarajan and H. Levine (2019). "Hybrid epithelial/mesenchymal phenotypes promote metastasis and therapy resistance across carcinomas." Pharmacol Ther 194: 161-184.

Jolly, M. K., S. C. Tripathi, J. A. Somarelli, S. M. Hanash and H. Levine (2017). "Epithelial/mesenchymal plasticity: how have quantitative mathematical models helped improve our understanding?" Mol Oncol 11(7): 739-754.

Jolly, M. K., C. Ward, M. S. Eapen, S. Myers, O. Hallgren, H. Levine and S. S. Sohal (2018). "Epithelial-mesenchymal transition, a spectrum of states: Role in lung development, homeostasis, and disease." Dev Dyn 247(3): 346-358.

Jonasson, E., S. Ghannoum, E. Persson, J. Karlsson, T. Kroneis, E. Larsson, G. Landberg and A. Stahlberg (2019). "Identification of Breast Cancer Stem Cell Related Genes Using Functional Cellular Assays Combined With Single-Cell RNA Sequencing in MDA-MB-231 Cells." Front Genet 10: 500.

Jung, A., M. Schrauder, U. Oswald, C. Knoll, P. Sellberg, R. Palmqvist, G. Niedobitek, T. Brabletz and T. Kirchner (2001). "The invasion front of human colorectal adenocarcinomas shows co-localization of nuclear beta-catenin, cyclin D1, and p16INK4A and is a region of low proliferation." Am J Pathol 159(5): 1613-1617.

Junk, D. J., B. L. Bryson, J. M. Smigiel, N. Parameswaran, C. A. Bartel and M. W. Jackson (2017). "Oncostatin M promotes cancer cell plasticity through cooperative STAT3-SMAD3 signaling." Oncogene 36(28): 4001-4013.

Kalluri, R. and R. A. Weinberg (2009). "The basics of epithelial-mesenchymal transition." J Clin Invest 119(6): 1420-1428.

Kim, H., Q. Lin, P. M. Glazer and Z. Yun (2018). "The hypoxic tumor microenvironment in vivo selects the cancer stem cell fate of breast cancer cells." Breast Cancer Res 20(1): 16.

Korkaya, H., S. Liu and M. S. Wicha (2011). "Breast cancer stem cells, cytokine networks, and the tumor microenvironment." J Clin Invest 121(10): 3804-3809.

Kraning-Rush, C. M., J. P. Califano and C. A. Reinhart-King (2012). "Cellular traction stresses increase with increasing metastatic potential." PLoS One 7(2): e32572.

Kroger, C., A. Afeyan, J. Mraz, E. N. Eaton, F. Reinhardt, Y. L. Khodor, P. Thiru, B. Bierie, X. Ye, C. B. Burge and R. A. Weinberg (2019). "Acquisition of a hybrid E/M state is essential for tumorigenicity of basal breast cancer cells." Proc Natl Acad Sci U S A 116(15): 7353-7362.

Kwa, M. Q., K. M. Herum and C. Brakebusch (2019). "Cancer-associated fibroblasts: how do they contribute to metastasis?" Clin Exp Metastasis 36(2): 71-86.

Lau, E. Y., J. Lo, B. Y. Cheng, M. K. Ma, J. M. Lee, J. K. Ng, S. Chai, C. H. Lin, S. Y. Tsang, S. Ma, I. O. Ng and T. K. Lee (2016). "Cancer-Associated Fibroblasts Regulate Tumor-Initiating Cell Plasticity in Hepatocellular Carcinoma through c-Met/FRA1/HEY1 Signaling." Cell Rep 15(6): 1175-1189.

Lee, J. H., E. R. Daugharthy, J. Scheiman, R. Kalhor, J. L. Yang, T. C. Ferrante, R. Terry, S. S. Jeanty, C. Li, R. Amamoto, D. T. Peters, B. M. Turczyk, A. H. Marblestone, S. A. Inverso, A. Bernard, P. Mali, X. Rios, J. Aach and G. M. Church (2014). "Highly multiplexed subcellular RNA sequencing in situ." Science 343(6177): 1360-1363.

Lequeux, A., M. Z. Noman, M. Xiao, D. Sauvage, K. Van Moer, E. Viry, I. Bocci, M. Hasmim, M. Bosseler, G. Berchem and B. Janji (2019). "Impact of hypoxic tumor microenvironment and tumor cell plasticity on the expression of immune checkpoints." Cancer Lett 458: 13-20.

Lewis, P. W., M. M. Muller, M. S. Koletsky, F. Cordero, S. Lin, L. A. Banaszynski, B. A. Garcia, T. W. Muir, O. J. Becher and C. D. Allis (2013). "Inhibition of PRC2 activity by a gain-of-function H3 mutation found in pediatric glioblastoma." Science 340(6134): 857-861.

Little, S. E., S. Popov, A. Jury, D. A. Bax, L. Doey, S. Al-Sarraj, J. M. Jurgensmeier and C. Jones (2012). "Receptor tyrosine kinase genes amplified in glioblastoma exhibit a mutual exclusivity in variable proportions reflective of individual tumor heterogeneity." Cancer Res 72(7): 1614-1620.

Liu, A., X. Yu and S. Liu (2013). "Pluripotency transcription factors and cancer stem cells: small genes make a big difference." Chin J Cancer 32(9): 483-487.

Liu, L., C. Liu, A. Quintero, L. Wu, Y. Yuan, M. Wang, M. Cheng, L. Leng, L. Xu, G. Dong, R. Li, Y. Liu, X. Wei, J. Xu, X. Chen, H. Lu, D. Chen, Q. Wang, Q. Zhou, X. Lin, G. Li, S. Liu, Q. Wang, H. 
Wang, J. L. Fink, Z. Gao, X. Liu, Y. Hou, S. Zhu, H. Yang, Y. Ye, G. Lin, F. Chen, C. Herrmann, R. Eils, Z. Shang and X. Xu (2019). "Deconvolution of single-cell multi-omics layers reveals regulatory heterogeneity." Nat Commun 10(1): 470.

Liu, S., Y. Cong, D. Wang, Y. Sun, L. Deng, Y. Liu, R. Martin-Trevino, L. Shang, S. P. McDermott, M. D. Landis, S. Hong, A. Adams, R. D'Angelo, C. Ginestier, E. Charafe-Jauffret, S. G. Clouthier, D. Birnbaum, S. T. Wong, M. Zhan, J. C. Chang and M. S. Wicha (2014). "Breast cancer stem cells transition between epithelial and mesenchymal states reflective of their normal counterparts." Stem Cell Reports 2(1): 78-91.

Liu, T. J., B. C. Sun, X. L. Zhao, X. M. Zhao, T. Sun, Q. Gu, Z. Yao, X. Y. Dong, N. Zhao and N. Liu (2013). "CD133+ cells with cancer stem cell characteristics associates with vasculogenic mimicry in triple-negative breast cancer." Oncogene 32(5): 544-553.

Liu, Z., Y. Lee, J. Jang, Y. Li, X. Han, K. Yokoi, M. Ferrari, L. Zhou and L. Qin (2015). "Microfluidic cytometric analysis of cancer cell transportability and invasiveness." Sci Rep 5: 14272.

Macaulay, I. C., C. P. Ponting and T. Voet (2017). "Single-Cell Multiomics: Multiple Measurements from Single Cells." Trends Genet 33(2): 155-168.

Malta, T. M., A. Sokolov, A. J. Gentles, T. Burzykowski, L. Poisson, J. N. Weinstein, B. Kaminska, J. Huelsken, L. Omberg, O. Gevaert, A. Colaprico, P. Czerwinska, S. Mazurek, L. Mishra, H. Heyn, A. Krasnitz, A. K. Godwin, A. J. Lazar, N. Cancer Genome Atlas Research, J. M. Stuart, K. A. Hoadley, P. W. Laird, H. Noushmehr and M. Wiznerowicz (2018). "Machine Learning Identifies Stemness Features Associated with Oncogenic Dedifferentiation." Cell 173(2): 338-354 e315.

Mani, S. A., W. Guo, M. J. Liao, E. N. Eaton, A. Ayyanan, A. Y. Zhou, M. Brooks, F. Reinhard, C. C. Zhang, M. Shipitsin, L. L. Campbell, K. Polyak, C. Brisken, J. Yang and R. A. Weinberg (2008). "The epithelial-mesenchymal transition generates cells with properties of stem cells." Cell 133(4): 704-715. Marjanovic, N. D., R. A. Weinberg and C. L. Chaffer (2013). "Cell plasticity and heterogeneity in cancer." Clin Chem 59(1): 168-179.

Martin, P., Y. N. Liu, R. Pierce, W. Abou-Kheir, O. Casey, V. Seng, D. Camacho, R. M. Simpson and K. Kelly (2011). "Prostate epithelial Pten/TP53 loss leads to transformation of multipotential progenitors and epithelial to mesenchymal transition." Am J Pathol 179(1): 422-435.

McGranahan, N. and C. Swanton (2017). "Clonal Heterogeneity and Tumor Evolution: Past, Present, and the Future." Cell 168(4): 613-628.

Mooney, S. M., V. Talebian, M. K. Jolly, D. Jia, M. Gromala, H. Levine and B. J. McConkey (2017). "The GRHL2/ZEB Feedback Loop-A Key Axis in the Regulation of EMT in Breast Cancer." J Cell Biochem 118(9): 2559-2570.

Moreira, M. P., F. A. Brayner, L. C. Alves, G. D. Cassali and L. M. Silva (2019). "Phenotypic, structural, and ultrastructural analysis of triple-negative breast cancer cell lines and breast cancer stem cell subpopulation." Eur Biophys J 48(7): 673-684.

Morrison, S. J. and A. C. Spradling (2008). "Stem cells and niches: mechanisms that promote stem cell maintenance throughout life." Cell 132(4): 598-611.

Mourao, L., G. Jacquemin, M. Huyghe, W. J. Nawrocki, N. Menssouri, N. Servant and S. Fre (2019). "Lineage tracing of Notch1-expressing cells in intestinal tumours reveals a distinct population of cancer stem cells." Sci Rep 9(1): 888.

Nallanthighal, S., J. P. Heiserman and D. J. Cheon (2019). "The Role of the Extracellular Matrix in Cancer Stemness." Front Cell Dev Biol 7: 86.

Nath, B., A. P. Bidkar, V. Kumar, A. Dalal, M. K. Jolly, S. S. Ghosh and G. Biswas (2019). "Deciphering Hydrodynamic and Drug-Resistant Behaviors of Metastatic EMT Breast Cancer Cells Moving in a Constricted Microcapillary." J Clin Med 8(8).

Navin, N. E. (2015). "The first five years of single-cell cancer genomics and beyond." Genome Res 25(10): 1499-1507.

Ogden, A. T., A. E. Waziri, R. A. Lochhead, D. Fusco, K. Lopez, J. A. Ellis, J. Kang, M. Assanah, G. M. McKhann, M. B. Sisti, P. C. McCormick, P. Canoll and J. N. Bruce (2008). "Identification of A2B5+CD133- tumor-initiating cells in adult human gliomas." Neurosurgery 62(2): 505-514; discussion 514-505.

Oshima, N., Y. Yamada, S. Nagayama, K. Kawada, S. Hasegawa, H. Okabe, Y. Sakai and T. Aoi (2014). "Induction of cancer stem cell properties in colon cancer cells by defined factors." PLoS One 9(7): e101735. 
Pastushenko, I., A. Brisebarre, A. Sifrim, M. Fioramonti, T. Revenco, S. Boumahdi, A. Van Keymeulen, D. Brown, V. Moers, S. Lemaire, S. De Clercq, E. Minguijon, C. Balsat, Y. Sokolow, C. Dubois, F. De Cock, S. Scozzaro, F. Sopena, A. Lanas, N. D'Haene, I. Salmon, J. C. Marine, T. Voet, P. A. Sotiropoulou and C. Blanpain (2018). "Identification of the tumour transition states occurring during EMT." Nature 556(7702): 463-468.

Patel, A. P., I. Tirosh, J. J. Trombetta, A. K. Shalek, S. M. Gillespie, H. Wakimoto, D. P. Cahill, B. V. Nahed, W. T. Curry, R. L. Martuza, D. N. Louis, O. Rozenblatt-Rosen, M. L. Suva, A. Regev and B. E. Bernstein (2014). "Single-cell RNA-seq highlights intratumoral heterogeneity in primary glioblastoma." Science 344(6190): 1396-1401.

Pattabiraman, D. R. and R. A. Weinberg (2014). "Tackling the cancer stem cells - what challenges do they pose?" Nat Rev Drug Discov 13(7): 497-512.

Peltanova, B., M. Raudenska and M. Masarik (2019). "Effect of tumor microenvironment on pathogenesis of the head and neck squamous cell carcinoma: a systematic review." Mol Cancer 18(1): 63.

Poli, V., L. Fagnocchi and A. Zippo (2018). "Tumorigenic Cell Reprogramming and Cancer Plasticity: Interplay between Signaling, Microenvironment, and Epigenetics." Stem Cells Int 2018: 4598195.

Prager, B. C., Q. Xie, S. Bao and J. N. Rich (2019). "Cancer Stem Cells: The Architects of the Tumor Ecosystem." Cell Stem Cell 24(1): 41-53.

Prasetyanti, P. R. and J. P. Medema (2017). "Intra-tumor heterogeneity from a cancer stem cell perspective." Mol Cancer 16(1): 41.

Puram, S. V., A. S. Parikh and I. Tirosh (2018). "Single cell RNA-seq highlights a role for a partial EMT in head and neck cancer." Mol Cell Oncol 5(3): e1448244.

Puram, S. V., I. Tirosh, A. S. Parikh, A. P. Patel, K. Yizhak, S. Gillespie, C. Rodman, C. L. Luo, E. A. Mroz, K. S. Emerick, D. G. Deschler, M. A. Varvares, R. Mylvaganam, O. Rozenblatt-Rosen, J. W. Rocco, W. C. Faquin, D. T. Lin, A. Regev and B. E. Bernstein (2017). "Single-Cell Transcriptomic Analysis of Primary and Metastatic Tumor Ecosystems in Head and Neck Cancer." Cell 171(7): 16111624 e1624.

Quail, D. F. and J. A. Joyce (2013). "Microenvironmental regulation of tumor progression and metastasis." Nat Med 19(11): 1423-1437.

Quintana, E., M. Shackleton, H. R. Foster, D. R. Fullen, M. S. Sabel, T. M. Johnson and S. J. Morrison (2010). "Phenotypic heterogeneity among tumorigenic melanoma cells from patients that is reversible and not hierarchically organized." Cancer Cell 18(5): 510-523.

Rheinbay, E., M. L. Suva, S. M. Gillespie, H. Wakimoto, A. P. Patel, M. Shahid, O. Oksuz, S. D. Rabkin, R. L. Martuza, M. N. Rivera, D. N. Louis, S. Kasif, A. S. Chi and B. E. Bernstein (2013). "An aberrant transcription factor network essential for Wnt signaling and stem cell maintenance in glioblastoma." Cell Rep 3(5): 1567-1579.

Rich, J. N. (2016). "Cancer stem cells: understanding tumor hierarchy and heterogeneity." Medicine (Baltimore) 95(1 Suppl 1): S2-7.

Rios, A. C., B. D. Capaldo, F. Vaillant, B. Pal, R. van Ineveld, C. A. Dawson, Y. Chen, E. Nolan, N. Y. Fu, D. Group, F. C. Jackling, S. Devi, D. Clouston, L. Whitehead, G. K. Smyth, S. N. Mueller, G. J. Lindeman and J. E. Visvader (2019). "Intraclonal Plasticity in Mammary Tumors Revealed through Large-Scale Single-Cell Resolution 3D Imaging." Cancer Cell 35(4): 618-632 e616.

Roesch, A., M. Fukunaga-Kalabis, E. C. Schmidt, S. E. Zabierowski, P. A. Brafford, A. Vultur, D. Basu, P. Gimotty, T. Vogt and M. Herlyn (2010). "A temporarily distinct subpopulation of slow-cycling melanoma cells is required for continuous tumor growth." Cell 141(4): 583-594.

Roy Choudhury, A., S. Gupta, P. K. Chaturvedi, N. Kumar and D. Pandey (2019). "Mechanobiology of Cancer Stem Cells and Their Niche." Cancer Microenviron 12(1): 17-27.

Saha, M., S. Kumar, S. Bukhari, S. A. Balaji, P. Kumar, S. K. Hindupur and A. Rangarajan (2018). "AMPK-Akt Double-Negative Feedback Loop in Breast Cancer Cells Regulates Their Adaptation to Matrix Deprivation." Cancer Res 78(6): 1497-1510.

Saliba, A. E., L. Saias, E. Psychari, N. Minc, D. Simon, F. C. Bidard, C. Mathiot, J. Y. Pierga, V. Fraisier, J. Salamero, V. Saada, F. Farace, P. Vielh, L. Malaquin and J. L. Viovy (2010). "Microfluidic sorting and multimodal typing of cancer cells in self-assembled magnetic arrays." Proc Natl Acad Sci U S A 107(33): 14524-14529. 
Santoro, A., T. Vlachou, L. Luzi, G. Melloni, L. Mazzarella, E. D'Elia, X. Aobuli, C. E. Pasi, L. Reavie, P. Bonetti, S. Punzi, L. Casoli, A. Sabo, M. C. Moroni, G. I. Dellino, B. Amati, F. Nicassio, L. Lanfrancone and P. G. Pelicci (2019). "p53 Loss in Breast Cancer Leads to Myc Activation, Increased Cell Plasticity, and Expression of a Mitotic Signature with Prognostic Value." Cell Rep 26(3): 624-638 e628.

Satija, R., J. A. Farrell, D. Gennert, A. F. Schier and A. Regev (2015). "Spatial reconstruction of singlecell gene expression data." Nat Biotechnol 33(5): 495-502.

Schmalhofer, O., S. Brabletz and T. Brabletz (2009). "E-cadherin, beta-catenin, and ZEB1 in malignant progression of cancer." Cancer Metastasis Rev 28(1-2): 151-166.

Sehl, M. E. and M. S. Wicha (2018). "Modeling of Interactions between Cancer Stem Cells and their Microenvironment: Predicting Clinical Response." Methods Mol Biol 1711: 333-349.

Sellerio, A. L., E. Ciusani, N. B. Ben-Moshe, S. Coco, A. Piccinini, C. R. Myers, J. P. Sethna, C. Giampietro, S. Zapperi and C. A. M. La Porta (2015). "Overshoot during phenotypic switching of cancer cell populations." Sci Rep 5: 15464.

Shackleton, M., E. Quintana, E. R. Fearon and S. J. Morrison (2009). "Heterogeneity in cancer: cancer stem cells versus clonal evolution." Cell 138(5): 822-829.

Shah, M., R. Cardenas, B. Wang, J. Persson, N. P. Mongan, A. Grabowska and C. Allegrucci (2017). "HOXC8 regulates self-renewal, differentiation and transformation of breast cancer stem cells." Mol Cancer 16(1): 38.

Sharma, A., E. Y. Cao, V. Kumar, X. Zhang, H. S. Leong, A. M. L. Wong, N. Ramakrishnan, M. Hakimullah, H. M. V. Teo, F. T. Chong, S. Chia, M. T. Thangavelu, X. L. Kwang, R. Gupta, J. R. Clark, G. Periyasamy, N. G. Iyer and R. DasGupta (2018). "Longitudinal single-cell RNA sequencing of patient-derived primary cells reveals drug-induced infidelity in stem cell hierarchy." Nat Commun 9(1): 4931.

Shibue, T. and R. A. Weinberg (2017). "EMT, CSCs, and drug resistance: the mechanistic link and clinical implications." Nat Rev Clin Oncol 14(10): 611-629.

Singh, S. K., C. Hawkins, I. D. Clarke, J. A. Squire, J. Bayani, T. Hide, R. M. Henkelman, M. D. Cusimano and P. B. Dirks (2004). "Identification of human brain tumour initiating cells." Nature 432(7015): 396-401.

Singla, M., A. Kumar, A. Bal, S. Sarkar and S. Bhattacharyya (2018). "Epithelial to mesenchymal transition induces stem cell like phenotype in renal cell carcinoma cells." Cancer Cell Int 18: 57.

Skylaki, S., O. Hilsenbeck and T. Schroeder (2016). "Challenges in long-term imaging and quantification of single-cell dynamics." Nat Biotechnol 34(11): 1137-1144.

Somasundaram, R., J. Villanueva and M. Herlyn (2012). "Intratumoral heterogeneity as a therapy resistance mechanism: role of melanoma subpopulations." Adv Pharmacol 65: 335-359.

Son, M. J., K. Woolard, D. H. Nam, J. Lee and H. A. Fine (2009). "SSEA-1 is an enrichment marker for tumor-initiating cells in human glioblastoma." Cell Stem Cell 4(5): 440-452.

Srinivasan, S., V. Ashok, S. Mohanty, A. Das, S. Das, S. Kumar, S. Sen and R. Purwar (2017). "Blockade of Rho-associated protein kinase (ROCK) inhibits the contractility and invasion potential of cancer stem like cells." Oncotarget 8(13): 21418-21428.

Suhail, Y., M. P. Cain, K. Vanaja, P. A. Kurywchak, A. Levchenko, R. Kalluri and Kshitiz (2019). "Systems Biology of Cancer Metastasis." Cell Syst 9(2): 109-127.

Sun, J., Q. Luo, L. Liu, B. Zhang, Y. Shi, Y. Ju and G. Song (2016). "Biomechanical profile of cancer stem-like cells derived from MHCC97H cell lines." J Biomech 49(1): 45-52.

Suva, M. L., E. Rheinbay, S. M. Gillespie, A. P. Patel, H. Wakimoto, S. D. Rabkin, N. Riggi, A. S. Chi, D. P. Cahill, B. V. Nahed, W. T. Curry, R. L. Martuza, M. N. Rivera, N. Rossetti, S. Kasif, S. Beik, S. Kadri, I. Tirosh, I. Wortman, A. K. Shalek, O. Rozenblatt-Rosen, A. Regev, D. N. Louis and B. E. Bernstein (2014). "Reconstructing and reprogramming the tumor-propagating potential of glioblastoma stem-like cells." Cell 157(3): 580-594.

Suva, M. L. and I. Tirosh (2019). "Single-Cell RNA Sequencing in Cancer: Lessons Learned and Emerging Challenges." Mol Cell 75(1): 7-12.

Swaminathan, V., K. Mythreye, E. T. O'Brien, A. Berchuck, G. C. Blobe and R. Superfine (2011). "Mechanical stiffness grades metastatic potential in patient tumor cells and in cancer cell lines." $\underline{\text { Cancer }}$ Res 71(15): 5075-5080. 
Swartz, M. A., N. Iida, E. W. Roberts, S. Sangaletti, M. H. Wong, F. E. Yull, L. M. Coussens and Y. A. DeClerck (2012). "Tumor microenvironment complexity: emerging roles in cancer therapy." Cancer Res 72(10): 2473-2480.

Tang, D. G. (2012). "Understanding cancer stem cell heterogeneity and plasticity." Cell Res 22(3): 457472.

Tripathi, S. C., J. F. Fahrmann, M. Celiktas, M. Aguilar, K. D. Marini, M. K. Jolly, H. Katayama, H. Wang, E. N. Murage, J. B. Dennison, D. N. Watkins, H. Levine, E. J. Ostrin, A. Taguchi and S. M. Hanash (2017). "MCAM Mediates Chemoresistance in Small-Cell Lung Cancer via the PI3K/AKT/SOX2 Signaling Pathway." Cancer Res 77(16): 4414-4425.

Tschaharganeh, D. F., W. Xue, D. F. Calvisi, M. Evert, T. V. Michurina, L. E. Dow, A. Banito, S. F. Katz, E. R. Kastenhuber, S. Weissmueller, C. H. Huang, A. Lechel, J. B. Andersen, D. Capper, L. Zender, T. Longerich, G. Enikolopov and S. W. Lowe (2014). "p53-dependent Nestin regulation links tumor suppression to cellular plasticity in liver cancer." Cell 158(3): 579-592.

Turashvili, G. and E. Brogi (2017). "Tumor Heterogeneity in Breast Cancer." Front Med (Lausanne) 4: 227.

Vermeulen, L., F. de Sousa e Melo, D. J. Richel and J. P. Medema (2012). "The developing cancer stem-cell model: clinical challenges and opportunities." Lancet Oncol 13(2): e83-89.

Wainwright, E. N. and P. Scaffidi (2017). "Epigenetics and Cancer Stem Cells: Unleashing, Hijacking, and Restricting Cellular Plasticity." Trends Cancer 3(5): 372-386.

Wang, J., P. O. Sakariassen, O. Tsinkalovsky, H. Immervoll, S. O. Boe, A. Svendsen, L. Prestegarden, G. Rosland, F. Thorsen, L. Stuhr, A. Molven, R. Bjerkvig and P. O. Enger (2008). "CD133 negative glioma cells form tumors in nude rats and give rise to CD133 positive cells." Int J Cancer 122(4): 761 768.

Wen, Y., J. Cai, Y. Hou, Z. Huang and Z. Wang (2017). "Role of EZH2 in cancer stem cells: from biological insight to a therapeutic target." Oncotarget 8(23): 37974-37990.

Wolfson, B., G. Eades and Q. Zhou (2015). "Adipocyte activation of cancer stem cell signaling in breast cancer." World J Biol Chem 6(2): 39-47.

Yamaguchi, H. and M. C. Hung (2014). "Regulation and Role of EZH2 in Cancer." Cancer Res Treat 46(3): 209-222.

Yuan, G. C., L. Cai, M. Elowitz, T. Enver, G. Fan, G. Guo, R. Irizarry, P. Kharchenko, J. Kim, S. Orkin, J. Quackenbush, A. Saadatpour, T. Schroeder, R. Shivdasani and I. Tirosh (2017). "Challenges and emerging directions in single-cell analysis." Genome Biol 18(1): 84.

Yuan, Y. (2016). "Spatial Heterogeneity in the Tumor Microenvironment." Cold Spring Harb Perspect Med 6(8).

Zanotelli, M. R., Z. E. Goldblatt, J. P. Miller, F. Bordeleau, J. Li, J. A. VanderBurgh, M. C. Lampi, M. R. King and C. A. Reinhart-King (2018). "Regulation of ATP utilization during metastatic cell migration by collagen architecture." Mol Biol Cell 29(1): 1-9.

Zhang, W., K. Kai, D. S. Choi, T. Iwamoto, Y. H. Nguyen, H. Wong, M. D. Landis, N. T. Ueno, J. Chang and L. Qin (2012). "Microfluidics separation reveals the stem-cell-like deformability of tumorinitiating cells." Proc Natl Acad Sci U S A 109(46): 18707-18712.

Zhang, Y., B. Sun, X. Zhao, Z. Liu, X. Wang, X. Yao, X. Dong and J. Chi (2013). "Clinical significances and prognostic value of cancer stem-like cells markers and vasculogenic mimicry in renal cell carcinoma." J Surg Oncol 108(6): 414-419.

Zhang, Y., M. Wu, X. Han, P. Wang and L. Qin (2015). "High-Throughput, Label-Free Isolation of Cancer Stem Cells on the Basis of Cell Adhesion Capacity." Angew Chem Int Ed Engl 54(37): 1083810842.

Zheng, H., Y. Pomyen, M. O. Hernandez, C. Li, F. Livak, W. Tang, H. Dang, T. F. Greten, J. L. Davis, Y. Zhao, M. Mehta, Y. Levin, J. Shetty, B. Tran, A. Budhu and X. W. Wang (2018). "Single-cell analysis reveals cancer stem cell heterogeneity in hepatocellular carcinoma." Hepatology 68(1): 127140.

Zomer, A., S. I. Ellenbroek, L. Ritsma, E. Beerling, N. Vrisekoop and J. Van Rheenen (2013). "Intravital imaging of cancer stem cell plasticity in mammary tumors." Stem Cells 31(3): 602-606. 


\section{Figures}

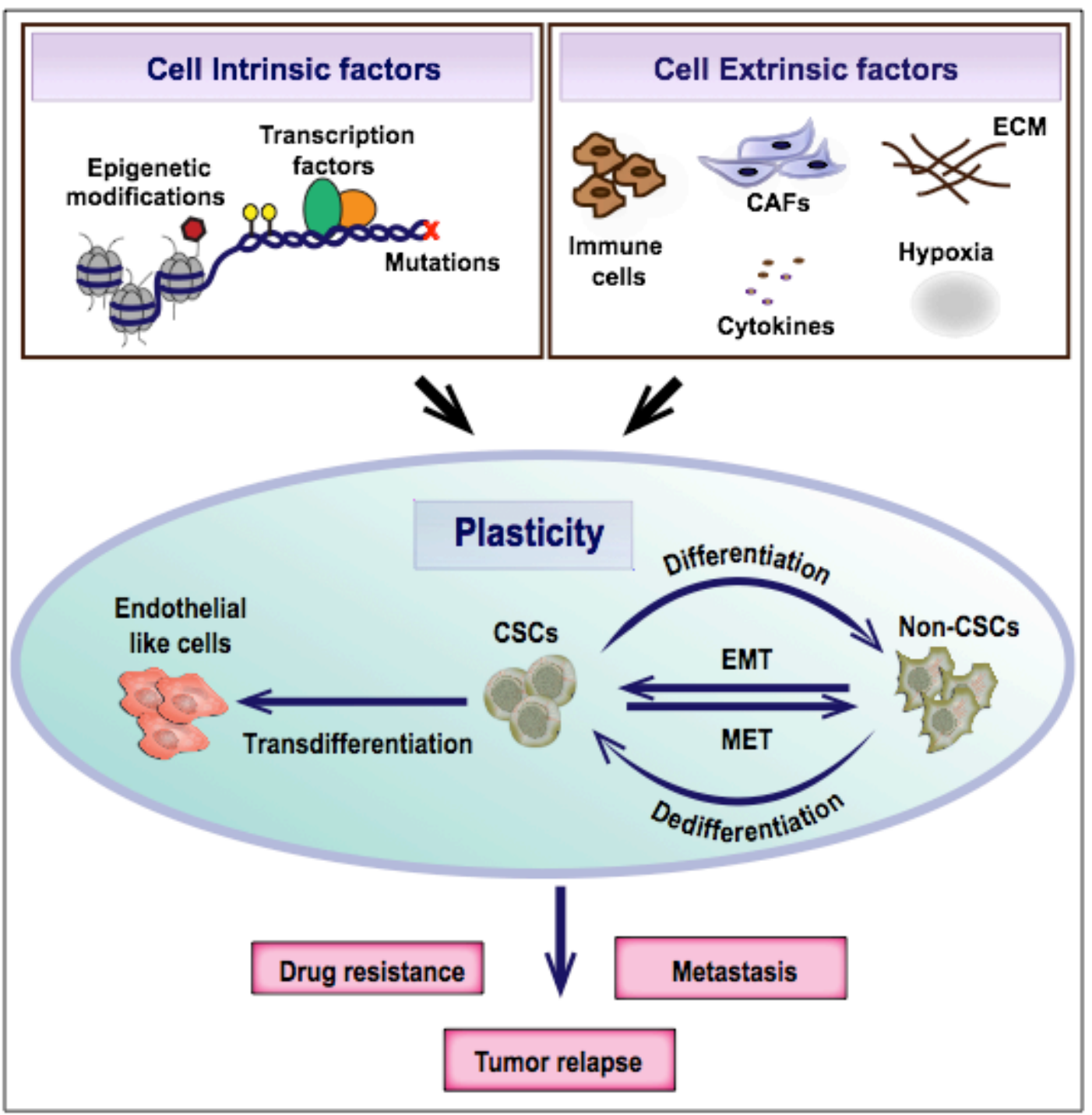

Fig. 1. Cancer stem cell plasticity is the ability to dynamically switch between CSC and non-CSC states. It is a complex process regulated by both cell intrinsic and extrinsic factors. Plasticity plays an important role in the evolution of therapeutic resistance, tumor relapse and metastasis. 